\title{
Uterine leiomyosarcoma in a cat
}

\author{
Hyemin $\mathrm{Na}^{1}$, Donghak Choi ${ }^{2}$, Woo-Chan Son ${ }^{3}$, Kija Lee ${ }^{1, *}$ \\ ${ }^{1}$ College of Veterinary Medicine, Kyungpook National University, Daegu 41566, Korea \\ ${ }^{2}$ Dongin Animal Clinic, Daegu 41946, Korea \\ ${ }^{3}$ Department of Pathology, Asan Medical Center, University of Ulsan College of Medicine, Seoul 05505, Korea
}

\begin{abstract}
A 16-year-old cat presented with a 2-week history of anorexia and lethargy. Radiography revealed a soft-tissue opacity, heart-shaped mass between the descending colon and urinary bladder. Ultrasonography showed a large uterine body with a heterogeneously hypoechoic, thickened wall and hypoechoic intraluminal fluid. Computed tomography revealed a large, fluid-filled uterine mass with contrast enhancement, without evidence of regional lymph node or pulmonary metastasis. Ovariohysterectomy was performed and leiomyosarcoma was confirmed by histology. No notable abnormalities were observed during the 1-year postoperative follow-up periods. This report describes the diagnostic imaging and treatment of a rare case of feline uterine leiomyosarcoma.
\end{abstract}

Keywords: cats, tumors, reproductive system, uterus, leiomyosarcoma

*Corresponding author

Kija Lee

College of Veterinary Medicine, Kyungpook National University, 80 Daehak-ro, Buk-gu, Daegu 41566, Korea

Tel: $+82-53-950-5961$

Fax: +82-53-950-5955

E-mail: leekj@knu.ac.kr

ORCID

Hyemin $\mathrm{Na}$

https://orcid.org/0000-0001-6171-8970

Donghak Choi

https://orcid.org/0000-0002-6170-6707

Kija Lee

https://orcid.org/0000-0002-4649-809X

Woo-Chan Son

https://orcid.org/0000-0002-9642-5390

Conflict of Interest

The authors declare no conflicts of interest.

Received: December 18, 2019

Revise d: May 12, 2020

Accepted: June 4, 2020
Uterine tumors are rare in dogs and cats. Uterine tumors account for $0.3 \%$ to $0.4 \%$ of all canine tumors [1] and $0.29 \%$ of all feline tumors [2]. Adenocarcinoma and leiomyoma are the most commonly reported feline uterine tumors [2]. Adenoma, leiomyosarcoma, and lymphosarcoma of the feline uterus have also been reported. One uterine leiomyosarcoma was reported in a study of 13 cats with uterine neoplasia [2], and 4 cases of feline uterine leiomyosarcoma were described in other reports [3,4]; all of 5 cats were over 10 years old at diagnosis. No specific breed predilections have been reported. The clinical signs of feline uterine tumors are abnormal estrus cycles and vaginal discharge; however, the presentation can be non-specific, including weight loss, stranguria, constipation, abdominal distension, and vomiting $[1,3]$. Although the definitive diagnosis is confirmed by histopathologic examination, radiography, ultrasonography, and computed tomography (CT) are helpful for making the diagnosis, especially in patients with non-specific clinical signs. This case report describes the diagnostic imaging and treatment of uterine leiomyosarcoma in a cat.

A 16-year-old, intact female, domestic short hair cat was presented with 2week history of anorexia, lethargy, and weight loss from $4.0 \mathrm{~kg}$ to $2.65 \mathrm{~kg}$. Physical examination revealed depression and slight icterus. There was no enlargement of the superficial lymph nodes. The complete blood count was unremarkable. Serum chemistry showed increased alanine transaminase (775 $\mathrm{U} / \mathrm{L}$, reference range $12-130 \mathrm{U} / \mathrm{L})$, alkaline phosphatase $(175 \mathrm{U} / \mathrm{L}$, reference range $14-111 \mathrm{U} / \mathrm{L})$, and total bilirubin $(6.3 \mathrm{mg} / \mathrm{dL}$, reference range $0.1-0.5$ $\mathrm{mg} / \mathrm{dL})$.

Abdominal radiography identified a large, soft-tissue opacity, heart-shaped mass between the descending colon and urinary bladder, cranially displacing the small intestine (Fig. 1). There were no significant findings on thoracic radiography. Abdominal ultrasonography revealed a heterogeneously hypoechoic mass connected to the vagina, containing anechoic fluid (Fig. 2A, B). Color Doppler sonogram showed mild peripheral vascularization of the mass (Fig. $2 \mathrm{C})$. Both ovaries were enlarged and had anechoic follicles.

CT examination was performed using a 32-Multislice CT (Alexion ${ }^{\mathrm{TM}}$; Toshiba, Japan). The patient was positioned in dorsal recumbency on the CT table under general anesthesia. The scanning parameters were as follows: 120 $\mathrm{kV}, 200 \mathrm{~mA}, 1.0 \mathrm{~mm}$ slice thickness, and $0.75 \mathrm{sec}$ rotation time. A contrast 

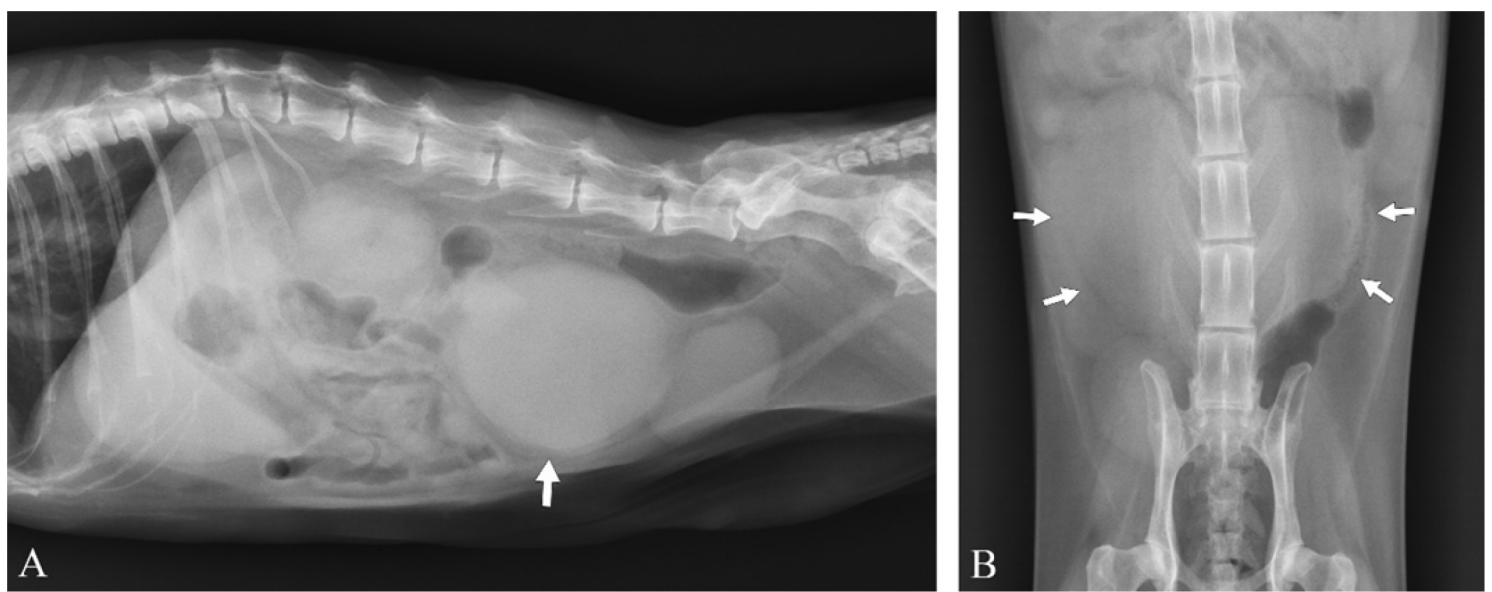

Fig. 1. Right lateral (A) and ventrodorsal (B) abdominal radiographs. A large heart-shaped, soft-tissue opacity mass (arrows) between the descending colon and urinary bladder is identified. The small intestine is displaced cranially by the mass.
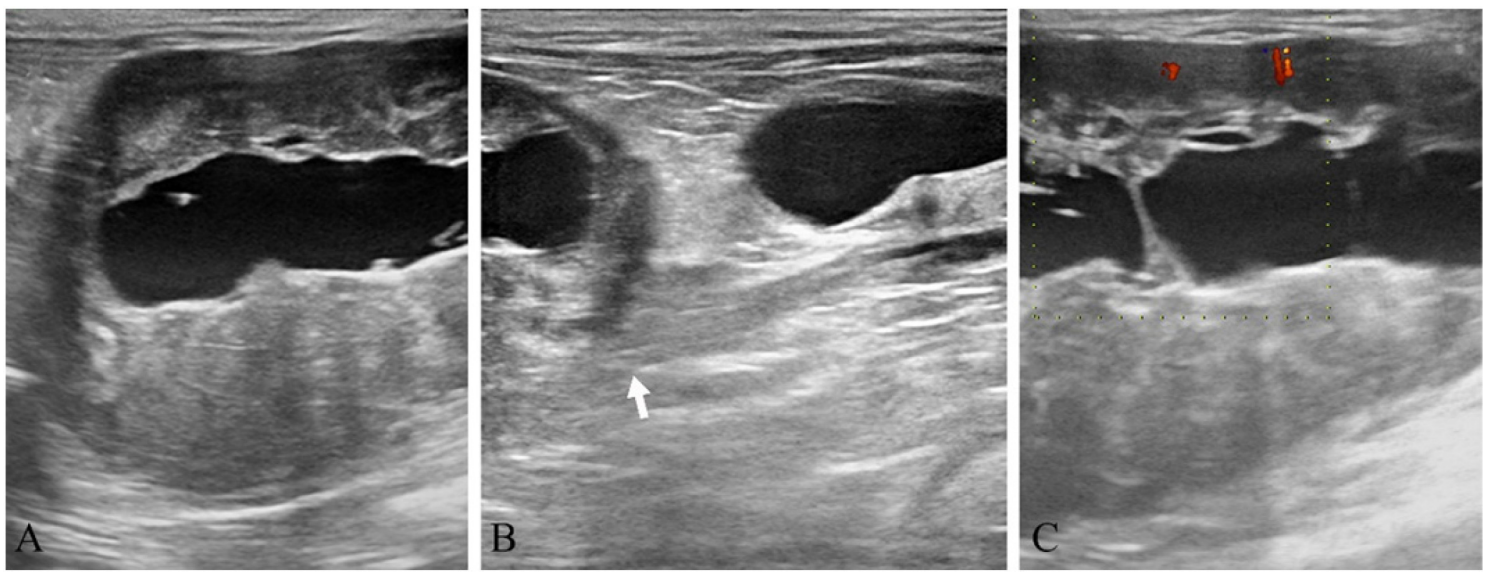

Fig. 2. Abdominal ultrasonographic images. The vagina (arrow) is connected to a heterogeneously hypoechoic, thick-walled mass containing anechoic fluid (A, B). Color Doppler image of the uterine mass shows the mild peripheral vascularization of the mass (C).

study was performed after intravenous injection of $600 \mathrm{mgI} /$ kg iohexol (Bonorex 300 Inj.; Daehan Pharm, Korea) for 20 sec using an autoinjector. Early- and delayed-phase postcontrast CT images were obtained 30 and $90 \mathrm{sec}$ after injection. A severely enlarged $(68.3 \times 57.4 \times 45.0 \mathrm{~mm})$, fluid-filled uterus with an irregularly thickened uterine wall was identified. On postcontrast study, the uterine wall showed heterogeneous contrast enhancement in early- and delayed-phase and the intraluminal fluid showed no contrast enhancement (Fig. 3). Both ovaries were enlarged with multiple follicles. The left kidney and small intestine were displaced cranially by the enlarged uterus. There was no evidence of abdominal regional lymphadenopathy or pulmonary metastasis. Based on radiography, ultrasound, and CT findings, the presumptive diagnosis was uterine tumor without metastasis.

Ovariohysterectomy was performed and postoperative histopathologic diagnosis of the mass was uterine leiomyosarcoma with pyometra (Fig. 4). Spindle cells with elongated, blunt-ended nuclei with granular chromatin, and abundant eosinophilic cytoplasm were found with moderate anisokaryosis. Densely arranged, mildly pleomorphic ovoid to spindle cells with intensely eosinophilic cytoplasm were also detected. Medical treatment for icterus was also performed. After surgery and hospitalization, the clinical symptoms resolved. No notable abnormalities were observed after 1 year of postoperative follow-up.

Differentiation between leiomyoma and leiomyosarcoma is important for selecting from among the available conservative and surgical treatment modalities [5]. Also, presurgical awareness of possible leiomyosarcoma would help in treatment planning [5]. On ultrasonography, uterine leiomyosarcoma appears as a heterogeneous mass containing an anechoic area and hyperechoic foci [6]. However, ultrasonographic features of uterine leiomyosarcoma are similar to those of uterine leiomyoma, which show isoechoic to surrounding uterine tissue with or without anechoic cyst-like lesions and hyperechoic foci [6,7]. It would, therefore, appear that it is not possible to differentiate leiomyosarcoma and leiomyoma 

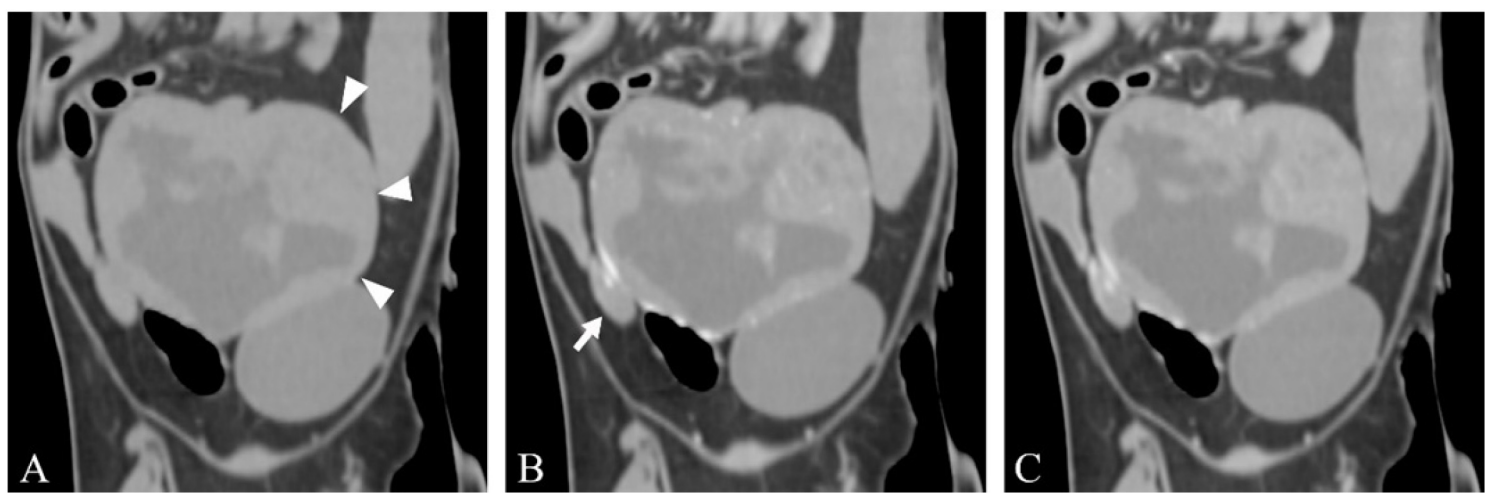

Fig. 3. Non-contrast (A) and postcontrast $(B, C)$ dorsal plane computed tomography of the caudal abdomen. A severely enlarged, fluidfilled uterus with an irregularly thickened wall showing heterogeneous contrast enhancement is identified. The uterine body mass (arrowheads) is connected to the uterine horn (arrow).
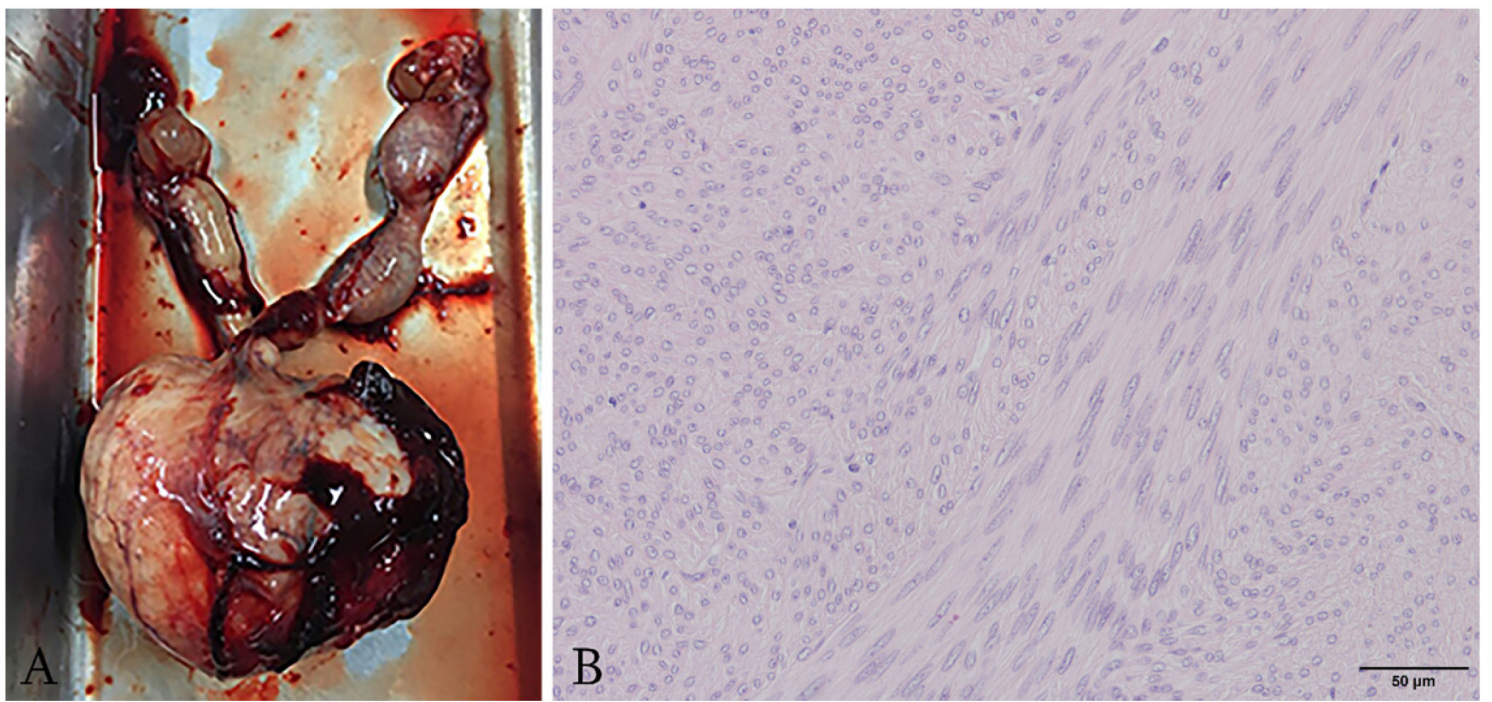

Fig. 4. Postsurgical image of the excised uterus (A) and histological section of the uterine mass (B). Spindle cells with elongated, blunt-ended nuclei with granular chromatin, and abundant eosinophilic cytoplasm were found with moderate anisokaryosis. Densely arranged, mildly pleomorphic ovoid to spindle cells with intensely eosinophilic cytoplasm were also detected (hematoxylin and eosin stain; bar $=50 \mu \mathrm{m})$.

from their ultrasonographic appearance alone [7]. In human medicine, color Doppler sonography has been reported to be effective in distinguishing uterine leiomyosarcoma from leiomyoma, although this is still controversial [5]. In a previous study comparing gray-scale and color Doppler sonography to differentiate uterine leiomyoma from leiomyosarcoma, the peripheral vascularity of leiomyoma was increased compared to that of normal myometrium and to that of the center of the tumor. In contrast, uterine leiomyosarcoma had a vascular distribution characterized by increased central vascularity [5]. In our study, mild peripheral vascularity of the uterus was detected, which differ from the results of the previous study in humans. Doppler sonographic studies to differentiate benign and malignant uterine tumors in small animals are lacking; further color Doppler ultrasonographic studies are warranted.
CT features of uterine leiomyosarcoma cases have not been reported in dogs and cats, but there are several reports in humans [8-10]. Uterine leiomyosarcoma in women appears as a large, slightly heterogeneous mass replacing normal uterus, with obvious enhancement and peripheral necrosis on early-phase contrast [9]. However, the CT features of leiomyosarcoma are non-specific compared to those of leiomyomas, lymphoma, and other types of sarcoma in humans [10]. Although other pathologic processes may resemble some of the CT findings of leiomyosarcoma, CT examination is still valuable for detecting the presence of pulmonary, mesenteric, omental, nodal, or soft-tissue metastases [10].

Previous feline malignant uterine tumors showed poor prognosis, in contrast to canine uterine leiomyosarcomas without metastasis reported good prognosis $[2,11,12]$. In previous studies, there were 1 feline uterine leiomyosarcoma 
without metastasis [2], and 4 feline uterine leiomyosarcomas with metastasis $[3,4]$. Among the previous cases of feline uterine leiomyosarcomas, the outcomes of 2 cats were reported: one cat was euthanized and no metastasis was found at necropsy [2]; the other was also euthanized because of abdominal metastasis found 1 month after ovariohysterectomy [3]. The cat in the present study had no evidence of metastasis of the time of diagnosis, which connoted a good prognosis. Data on the prognosis of cats with uterine tumors are scarce [2,3]. The present study adds to the limited available information for determining the prognosis of uterine leiomyosarcoma in cats.

Several reports in dogs have indicated that muscle tumors of the uterus, including leiomyosarcoma and leiomyoma, may play a role in the pathogenesis of pyometra. In a previous report, a correlation between canine uterine leiomyosarcoma and pyometra was observed [6]. The possibility of a predisposition to infections was ascribed to immunosuppression and loss of local defense mechanisms by the malignant mass [6]. Further, uterine leiomyoma obstructs the cervix, and pyometra is caused by impairment of natural drainage of the cervix in dogs $[13,14]$. Similarly, in the present case, uterine leiomyosarcoma with pyometra was confirmed.

In conclusion, this is the first report describing the CT features of a rare case of uterine leiomyosarcoma in a cat. Diagnostic imaging including radiography, ultrasonography, and $\mathrm{CT}$ is useful for determining tumor origin and metastasis. The prognosis of uterine leiomyosarcoma without metastasis may be good after complete surgical resection, even if the tumor is malignant.

\section{References}

1. Brodey RS. Canine and feline neoplasia. Adv Vet Sci Comp Med 1970;14:309-354.

2. Miller MA, Ramos-Vara JA, Dickerson MF, Johnson GC, Pace LW, Kreeger JM, Turnquist SE, Turk JR. Uterine neoplasia in 13 cats. J Vet Diagn Invest 2003;15:515-522.

3. Cooper TK, Ronnett BM, Ruben DS, Zink MC. Uterine myxoid leiomyosarcoma with widespread metastases in a cat. Vet Pathol 2006;43:552-556.

4. Carpenter JL, Andrews LK, Holzworth J. Tumors and tumorlike lesions. In: Holzworth $\mathrm{J}$ (eds.). Disease of The Cat: Medicine and Surgery. pp. 406-596, WB Saunders, Philadelphia, 1987.

5. Exacoustos C, Romanini ME, Amadio A, Amoroso C, Szabolcs B, Zupi E, Arduini D. Can gray-scale and color Doppler sonography differentiate between uterine leiomyosarcoma and leiomyoma? J Clin Ultrasound 2007;35:449-457.

6. Tsioli VG, Gouletsou PG, Loukopoulos P, Zavlaris M, Galatos AD. Uterine leiomyosarcoma and pyometra in a dog. J Small Anim Pract 2011;52:121-124.

7. Patsikas M, Papazoglou LG, Jakovljevic S, Papaioannou NG, Papadopoulou PL, Soultani CB, Chryssogonidis IA, Kouskouras KA, Tziris NE, Charitanti AA. Radiographic and ultrasonographic findings of uterine neoplasms in nine dogs. J Am Anim Hosp Assoc 2014;50:330-337.

8. Vigone A, Giana M, Surico D, Leutner M, Surico N. Massive myxoid leiomyosarcoma of the uterus. Int J Gynecol Cancer 2005;15:564-567.

9. Qiu LL, Yu RS, Chen Y, Zhang Q. Sarcomas of abdominal organs: computed tomography and magnetic resonance imaging findings. Semin Ultrasound CT MR 2011;32:405-421.

10. McLeod AJ, Zornoza J, Shirkhoda A. Leiomyosarcoma: computed tomographic findings. Radiology 1984;152:133-136.

11. Thomson MJ, Britt TA. Reproductive system. In: Kudnig ST, Séguin B (eds.). Veterinary Surgical Oncology. pp. 341-364, Blackwell, Los Angeles, 2012.

12. Brodey RS, Roszel JF. Neoplasms of the canine uterus, vagina, and vulva: a clinicopathologic survey of 90 cases. J Am Vet Med Assoc 1967;151:1294-1307.

13. Shammi M, Shiju SM, Puskin RH, Sivashanker R, Suresh KR. Surgical management of uterine leiomyoma in a bitch. Tamilnadu J Vet Anim Sci 2010;6:181-182.

14. Mohan D, Maiti SK, Shivaraju S, Ramith KR, Sangeetha P, Bindhuja BV, Kumar N. Surgical management of multiple uterine tumours in a dog. MOJ Anat Physiol 2018;5:117-118. 